\title{
Stage I Oropharyngeal (p16-Negative) Carcinoma AJCC v8
}

National Cancer Institute

\section{Source}

National Cancer Institute. Stage I Oropharyngeal (p16-Negative) Carcinoma A/CC v8. NCI Thesaurus. Code C132996.

Stage I includes: T1, N0, M0. T1: Tumor $2 \mathrm{~cm}$ or smaller in greatest dimension. N0: No regional lymph node metastasis. M0: No distant metastasis. (AJCC 8th ed.) 